\title{
ANTERIOR CRUCIATE LIGAMENT INJURY: TREATMENT AND REHABILITATION. CURRENT PERSPECTIVES AND TRENDS
}

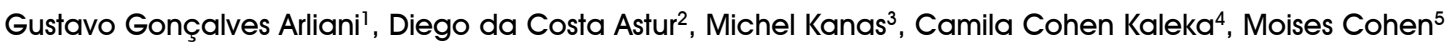

\section{ABSTRACT}

Objective: The aim of this study was to evaluate the procedures used by knee surgeons in Brazil for treating and rehabilitating anterior cruciate ligament injuries. Methods: A questionnaire consisting of 21 closed questions was developed, addressing topics relating to treatment and rehabilitation after anterior cruciate ligament reconstruction. The questionnaire was applied to Brazilian knee surgeons during the three days of the $42^{\text {nd }}$ Brazilian Congress of Orthopedics and Traumatology in 2010. Results: A total of 226 surgeons filled out the questionnaire completely. The most commonly used types of graft were hamstrings tendons and the central third of the ipsilateral patellar tendon, which were used by $82.3 \%$ and $53.5 \%$ of the sample, respectively. The technique of reconstruction with a single transtibial band was the first preference and was used by $66.4 \%$ of the participants. A period of 1 to 4 weeks between injury and surgical procedure was considered ideal by most participants (52.65\%). Complaints from patients that the knee was 'giving way' or unstable and presence of a positive pivot shift maneuver were the most decisive factors considered in making the decision to operate the patient. Patient satisfaction and absence of complaints of instability during the postoperative period were the criteria deemed to be most important for the surgery to be considered a success. Conclusions: There are clearly evolving trends in treating and rehabilitating the anterior cruciate ligament in Brazil. However, more prospective controlled studies are needed in order to evaluate the clinical and scientific benefits of these trends.

Keywords - Anterior Cruciate Ligament; Reconstruction; Rehabilitation; Orthopedics

\section{INTRODUCTION}

The anterior cruciate ligament (ACL) is a fundamental structure in the knee, given that it is important in limiting anterior instability and internal rotation of the tibia ${ }^{(1,2)}$. Tearing of this structure is the most common ligament injury in the knee, when only complete ligament tears are taken into consideration ${ }^{(3)}$. ACL lesions mainly affect young and active individuals and are characterized especially by joint instability ${ }^{(4)}$.

It is widely accepted that the ACL does not heal adequately after injury. Surgical reconstruction is today the standard treatment for athletes, and approximately 200,000 ACL reconstructions are performed every year in the United States, with direct costs estimated to be three billion dollars ${ }^{(4,5)}$.
Over the last few years, several randomized clinical trials and systematic reviews have been conducted with the aim of improving the treatment of this lesion and subsequent rehabilitation. However, there is still no consensus in the literature on this subject ${ }^{(6-8)}$.

The high incidence of this lesion and the great importance of the social and economic issues relating to it, together with the enormous divergences that exist in the literature on this subject, make it extremely important to assess the approaches and trends that exist in Brazil regarding this topic.

The aim of this study was to assess the approaches and procedures used by knee surgeons in Brazil for treating ACL lesions. From the results of this study, it may be possible to delineate national trends regarding this subject and guide future quality studies.

1 - Member of the Sports Traumatology Center (CETE), Department of Orthopedics and Traumatology, Federal University of São Paulo, São Paulo, SP, Brazil.

2 - Member of the Sports Traumatology Center (CETE), Department of Orthopedics and Traumatology, Federal University of São Paulo, São Paulo, SP, Brazil.

3 - Resident Physician in the Department of Orthopedics and Traumatology, Federal University of São Paulo, São Paulo, SP, Brazil.

4 - Physician in the Knee Group, School of Medical Sciences, Santa Casa de São Paulo, São Paulo, SP, Brazil.

5 - Adjunct Professor and Head of the Department of Orthopedics and Traumatology, Federal University of São Paulo, São Paulo, SP, Brazil.

Work performed at the Sports Traumatology Center, Department of Orthopedics and Traumatology, Federal University of São Paulo, SP, Brazil (DOT-Unifesp/EPM).

Correspondence: Rua Borges Lagoa 783, $5^{\circ}$ andar, Vila Clementino, 04038-032 São Paulo, SP. E-mail: ggarliani@hotmail.com

Work received for publication: March 8, 2011; accepted for publication: May 25, 2011.

The authors declare that there was no conflict of interest in conducting this work 


\section{MATERIAL AND METHODS}

This was a descriptive study in which a questionnaire was applied to a group of knee surgeons in Brazil. The questionnaire was drawn up and approved by the authors in such a way that it was easily comprehended and simple. It consisted of 21 closed questions that covered topics like the number of years of experience that the surgeon had and the annual number of ACL reconstructions performed, and a variety of issues relating to treatment and rehabilitation after ACL reconstruction (Annex 1).

The questionnaire was applied to Brazilian knee surgeons during the three days of the $42^{\text {nd }}$ Brazilian Congress of Orthopedics and Traumatology, in 2010. Only orthopedists who performed ACL reconstruction surgery filled out the questionnaire. In total, 241 questionnaires were filled out, of which 15 were excluded: three because the surgeon came from another country (Portugal, Bolivia and Peru) and another 12 because the questionnaire was filled out incompletely. In total, 226 questionnaires were completed filled out. To resolve possible doubts while the questionnaires were being filled out, two investigators were present during the entire period of applying the questionnaires.

From the data retrieved from the questionnaire, descriptive statistics on the variables involved were produced to characterize the sample.

The data were analyzed using the SPSS for Windows software, version 16.0, using a significance level of 5\%.

\section{RESULTS}

In total, 226 knee surgeons completely filled out the questionnaire and formed part of the sample analyzed. The distribution of the surgeons according to their region of origin is shown in Table 1. Regarding the surgeons' length of experience, the mean was $8.7( \pm 6.4)$ years, with a minimum of one year and a maximum of 30 years of experience. The results relating to the numbers of reconstructions performed per year in public and private clinics are shown in Table 2. The types of graft most used were flexor tendons (gracilis and semitendinosus), which were used by $82.3 \%$ of the individuals in the sample, and the central third of the patellar tendon ipsilateral to the lesion (53.5\%). Among the surgeons who used grafts from the flexor tendons, $61.5 \%$ preferred to use a vertical anterior incision for graft harvesting and $22.6 \%$, a horizontal/oblique ante- rior incision. Only $1.3 \%$ of the sample used a posterior incision in the flexion crease for graft harvesting. Regarding the graft fixation method, the majority of the surgeons used a metal interference screw (32.12\%) and a transverse pin $(32.12 \%)$ in the femur; and a metal interference screw $(45.16 \%)$ or absorbable screw $(45.52 \%)$ in the tibia. The reconstruction technique using a transtibial single band was preferred, and was used by $66.4 \%$ of the sample (Table 3 ).

Pretensioning of the graft during the operation was done by $77.4 \%$ of these specialists. A period of one to four weeks between the injury and carrying out the surgical procedure was considered to be ideal by a majority of the participants $(52.65 \%)$. Preoperative physiotherapy was routinely prescribed by $61.9 \%$ of the surgeons, but there was no correlation between use of preoperative physiotherapy and the time that the surgeons considered to be ideal for carrying out the procedure $(r=0.004$ and $p=0.94)$. The majority of the sample $(65.9 \%)$ referred their patients for physiotherapy within the first week after the surgery, and $89.8 \%$ of the physicians had a postoperative rehabilitation protocol. Regarding brace use after the operation, $71.7 \%$ of the physicians did not use this. Most of the surgeons who used this form of immobilization after the operation did so for a maximum of four weeks. Intra-articular infiltration of anesthetic and drains used at the end

Table 1 - Surgeons participating per region.

\begin{tabular}{c|c}
\hline Center-west & $26(11.5 \%)$ \\
\hline Northeast & $34(15 \%)$ \\
\hline North & $15(6.6 \%)$ \\
\hline Southeast & $123(54.4 \%)$ \\
\hline South & $28(12.4 \%)$ \\
\hline
\end{tabular}

Table 2 - Reconstructions per year.

\begin{tabular}{c|c|c}
\hline & Public & Private \\
\hline$<10$ & $32(14.2 \%)$ & $45(19.9 \%)$ \\
\hline $10-20$ & $56(24.8 \%)$ & $49(21.7 \%)$ \\
\hline $20-30$ & $34(15.0 \%)$ & $43(19.0 \%)$ \\
\hline $30-40$ & $16(7.1 \%)$ & $35(15.5 \%)$ \\
\hline$<40$ & $27(11.9 \%)$ & $42(18.6 \%)$ \\
\hline Not in this type of clinic & $41(18.1 \%)$ & $10(4.4 \%)$ \\
\hline
\end{tabular}

Table 3 - Technique used.

\begin{tabular}{c|c}
\hline Transtibial, single band & $150(66.4 \%)$ \\
\hline Transportal, single band & $49(21.7 \%)$ \\
\hline Double band & $27(11.9 \%)$ \\
\hline
\end{tabular}


of the surgery are methods that are still little used: respectively, $18.1 \%$ and $29.2 \%$ of the physicians were using them. Meniscal suturing is also infrequently used in our setting, such that $68.1 \%$ of the surgeons did not do this. Complaints of dislocation or instability by the patient and presence of a positive pivot-shift maneuver in the physical examination were the factors considered to be the most important determinants in deciding whether to operate the patient. Patient satisfaction and absence of complaints of instability after the operation were the criteria judged to be most important among this sample for considering that the surgery was successful. In relation to athletes' return to sports activities, $88.9 \%$ considered that a period of six months or more would be ideal. When the surgeons were asked about the need to perform surgery on a patient with the same level of activity as themselves, $92 \%$ of them said that they would indicate ACL reconstruction as the treatment option. When they were asked about surgery in the event of tearing their own ACL, $90.7 \%$ of the interviewees replied that they would accept the procedure. There was a significant correlation between the responses to these two questions $(r=0.24$ and $p=0.0001)$.

\section{DISCUSSION}

Some studies that aimed to evaluated perspectives and trends relating to treatment and rehabilitation of patients with ACL injuries were found in the literature $^{(9-11)}$. However, no such studies were found in the Brazilian literature. However, one study was recently conducted in Brazil with the aim of evaluating the treatment methods used in cases of lateral twisting of the ankle ${ }^{(12)}$.

In evaluating the distribution frequencies of the participating orthopedists according to their region of Brazil, we noted that participants from the southeastern region predominated, even though the study was conducted in the central-western region (in Brasília). We believe that that this may have occurred because there are greater numbers of knee surgery specialists in this region of Brazil.

It was seen in this study that the types of graft most used by Brazilian surgeons were the flexor tendons (gracilis and semitendinosus) and the central third of the patellar tendon ipsilateral to the lesion. These were also the grafts most used by orthopedists in the United Kingdom in a similar study conducted in $2001^{(11)}$.
However, several studies have demonstrated that there are no significant differences in measurements of ligament laxity and joint degeneration between the different graft types. Increasing graft laxity over time has been observed in different graft groups and thus choosing the graft continues to be at the surgeon's discretion ${ }^{(13-15)}$. Nonetheless, other studies (including a meta-analysis) have shown that reconstruction using the patellar tendon leads to knees with greater stability, with less anterior laxity and less rotational instability, in comparison with flexor tendons ${ }^{(16,17)}$. Another study comparing reconstructions with these two grafts concluded that grafts using the hamstring tendons present greater incidence of infection than do autografts and allografts from the patellar tendon ${ }^{(18)}$. There is still no consensus on this topic, but it is already known that excellent results can be obtained with both graft types.

Other graft types that were less often cited by the participants, like the central third of the quadriceps muscle and allografts, have also shown good results when used in ACL reconstructions. Thus, these can be considered to be good alternatives in reconstructing this ligament ${ }^{(19-21)}$.

Sensory abnormalities during the postoperative period following ACL reconstruction, due to lesions of the infrapatellar branch of the saphenous nerve that are caused while harvesting graft material from the flexor tendon, may affect up to $74 \%$ of the patients ${ }^{(22)}$. Some studies have demonstrated that the incision used in harvesting the graft material may influence the frequency of these lesions ${ }^{(22,23)}$. Even though vertical incisions are still the type most used in our setting, for harvesting grafts from the flexor tendons (61.5\%), some studies have shown that making an oblique incision gives rise to less risk of injury to the infrapatellar branch of the saphenous nerve $\mathrm{e}^{(22,23)}$.

The fixation method most used by the surgeons was a transverse pin with a metal interference screw in the femur and an absorbable or metal interference screw in the tibia. In the current literature, neither of these methods can be defined as superior to the other, and both of them present good results for graft fixation in ACL reconstruction ${ }^{(24-26)}$.

The reconstruction technique using a transtibial single band is still preferred in our setting (66.4\%). However, the current trend is pointing towards reconstruction of this ligament that is more anatomical, which is considered unlikely to be achieved using the 
transtibial technique, according to some studies ${ }^{(27,28)}$. Nevertheless, the theory that reconstruction with a double band would be superior to reconstruction with a single band is not supported, and even more so when this single tunnel is positioned more horizontally, as is done in the transportal technique ${ }^{(29,30)}$. Thus, there is now a need for further randomized clinical trials of good quality on this subject.

Pretensioning of the graft during the operation was performed by $77.4 \%$ of the specialists, even though it is stated in the literature that there are no postoperative differences between groups with and without pretensioning of the $\operatorname{graft}^{(31,32)}$.

A period of one to four weeks between the injury and performing the surgical procedure was considered to be ideal by the majority of our participants $(52.65 \%)$. However, in another study, the majority of the orthopedists in the United Kingdom considered that the ideal was a period of between one and six months before performing the surgery ${ }^{(11)}$. This difference probably occurred because no consensus has yet been reached in the worldwide literature regarding this topic. A systematic review did not find any differences in the results between patients who were operated early ( $<$ three weeks) or later on $(>\text { six weeks })^{(33)}$. One interesting point that we found was that although most of the surgeons considered that a period of one to four weeks was ideal, only $7.6 \%$ of them were able to carry out their operations within this period in public clinics, and only $47.9 \%$ in private clinics. This shows the difficulty that orthopedists face in conducting treatments on patients in public clinics, which are often overloaded. This is also seen to some extent in private clinics, probably due to difficult relationships with medical insurers and patients. Thus, approximately 38\% of the patients at public clinics undergo surgery more

\section{REFERENCES}

1. Matsumoto H, Suda Y, Otani T, Niki Y, Seedhom BB, Fujikawa K. Roles of the anterior cruciate ligament and the medial collateral ligament in preventing valgus instability. J Orthop Sci. 2001;6(1):28-32.

2. Sakane M, Fox RJ, Woo SL, Livesay GA, Li G, Fu FH. In situ forces in the anterior cruciate ligament and its bundles in response to anterior tibial loads. J Orthop Res. 1997;15(2):285-93.

3. Bottoni CR, Liddell TR, Trainor TJ, Freccero DM, Lindell KK. Postoperative range of motion following anterior cruciate ligament reconstruction using autograft hamstrings: a prospective, randomized clinical trial of early versus delayed reconstructions. Am J Sports Med. 2008;36(4):656-62.

4. Frobell RB, Roos EM, Roos HP, Ranstam J, Lohmander LS. A randomized trial of treatment for acute anterior cruciate ligament tears. $\mathrm{N}$ Engl J Med. 2010;363(4):331-42.

5. Duthon VB, Barea C, Abrassart S, Fasel JH, Fritschy D, Menetrey J. Ana-

Rev Bras Ortop. 2012;47(2):191-96 than one year after the injury, even though it is now known that a prolonged wait for surgery may cause additional cartilage and meniscus injuries ${ }^{(34)}$.

Regarding postoperative brace use, $71.7 \%$ of the physicians did not use them, which is supported by the current literature, in which use of functional braces after ACL reconstruction is not recommended ${ }^{(35)}$. The same results were found in the United Kingdom, where only $30 \%$ of the orthopedists immobilized their patients after the operation ${ }^{(11)}$.

Intra-articular infiltration of anesthetic and use of drains at the end of the surgical procedure are methods that are still little used in Brazil. Two randomized controlled studies have shown that routine use of drains after ACL reconstruction is not recommended, since no significant differences were found in the results. Moreover, drain removal is uncomfortable for the patient and is not risk-free ${ }^{(36,37)}$. On the other hand, another study demonstrated that use of intra-articular analgesia after the operation has a significant effect regarding reduction of the patient's use of medication over a 24-hour period, and that this effect is greater among male patients ${ }^{(38)}$.

Meniscal suturing is still infrequently performed in our setting (32\%). This is probably due to the high cost of the material used in most meniscal suturing techniques, and the greater difficulty in this treatment technique, compared with partial meniscectomy.

\section{CONCLUSION}

This study demonstrates that clear trends regarding ACL treatment and rehabilitation exist in Brazil. However, more controlled prospective studies are needed in order to evaluate the clinical and scientific benefit of these trends. tomy of the anterior cruciate ligament. Knee Surg Sports Traumatol Arthrosc. 2006;14(3):204-13.

6. Maffulli N, Longo UG, Denaro V. Anterior cruciate ligament tear. N Engl J Med. 2009;360(14):1463.

7. Lohmander LS, Englund PM, Dahl LL, Roos EM. The long-term consequence of anterior cruciate ligament and meniscus injuries: osteoarthritis. Am J Sports Med. 2007;35(10):1756-69.

8. Linko E, Harilainen A, Malmivaara A, Seitsalo S. Surgical versus conservative interventions for anterior cruciate ligament ruptures in adults. Cochrane Database Syst Rev. 2005(2):CD001356.

9. Beaufils P, Hulet C, Dhenain M, Nizard R, Nourissat G, Pujol N. Clinical practice guidelines for the management of meniscal lesions and isolated lesions of the anterior cruciate ligament of the knee in adults. Orthop Traumatol Surg Res. 2009;95(6):437-42. 
10. Kapoor B, Clement DJ, Kirkley A, Maffulli N. Current practice in the management of anterior cruciate ligament injuries in the United Kingdom. Br J Sports Med. 2004;38(5):542-4.

11. Francis A, Thomas RD, McGregor A. Anterior cruciate ligament rupture: reconstruction surgery and rehabilitation. A nation-wide survey of current practice. Knee. 2001;8(1):13-8.

12. Belangero PS, Tamaoki MJS, Nakama GY, Shoiti MV, Gomes RVF, Belloti JC. Como o ortopedista brasileiro trata entorse lateral aguda do tornozelo? Rev Bras Ortop. 2010;45(5):468-73.

13. Abdalla RJ, Monteiro DA, Dias L, Correia DM, Cohen M, Forgas A. Comparação entre os resultados obtidos na reconstrução do ligamento cruzado anterior do joelho utilizando dois tipos de enxertos autólogos: tendão patelar versus semitendíneo e grácil. Rev Bras Ortop. 2009;44(3):204-7.

14. Ahlden M, Kartus J, Ejerhed L, Karlsson J, Sernert N. Knee laxity measurements after anterior cruciate ligament reconstruction, using either bone-patellartendon-bone or hamstring tendon autografts, with special emphasis on comparison over time. Knee Surg Sports Traumatol Arthrosc. 2009;17(9):1117-24

15. Krych AJ, Jackson JD, Hoskin TL, Dahm DL. A meta-analysis of patellar tendon autograft versus patellar tendon allograft in anterior cruciate ligament reconstruction. Arthroscopy. 2008;24(3):292-8.

16. Biau DJ, Katsahian S, Kartus J, Harilainen A, Feller JA, Sajovic M, et al. Patellar tendon versus hamstring tendon autografts for reconstructing the anterio cruciate ligament: a meta-analysis based on individual patient data. Am J Sports Med. 2009;37(12):2470-8.

17. Heijne A, Werner S. A 2-year follow-up of rehabilitation after ACL reconstruction using patellar tendon or hamstring tendon grafts: a prospective randomised outcome study. Knee Surg Sports Traumatol Arthrosc. 2010;18(6):805-13.

18. Barker JU, Drakos MC, Maak TG, Warren RF, Williams RJ, 3rd, Allen AA. Effect of graft selection on the incidence of postoperative infection in anterior cruciate ligament reconstruction. Am J Sports Med. 2010;38(2):281-6

19. Edgar CM, Zimmer S, Kakar S, Jones H, Schepsis AA. Prospective comparison of auto and allograft hamstring tendon constructs for $A C L$ reconstruction. Clin Orthop Relat Res. 2008;466(9):2238-46.

20. Guimarães MV, Carvalho Junior LH, Terra DL. Reconstrução do ligamento cruzado anterior com o terço central do tendão do músculo quadríceps: análise de resultados após 10 anos. Rev Bras Ortop. 2009;44(4):306-12.

21. Sun K, Tian SQ, Zhang JH, Xia CS, Zhang CL, Yu TB. Anterior cruciate ligament reconstruction with bone-patellar tendon-bone autograft versus allograft. Arthroscopy. 2009;25(7):750-9.

22. Sanders B, Rolf R, McClelland W, Xerogeanes J. Prevalence of saphenous nerve injury after autogenous hamstring harvest: an anatomic and clinical study of sartorial branch injury. Arthroscopy. 2007;23(9):956-63.

23. Luo H, Yu JK, Ao YF, Yu CL, Peng LB, Lin CY, et al. Relationship between different skin incisions and the injury of the infrapatellar branch of the saphenous nerve during anterior cruciate ligament reconstruction. Chin Med J (Engl). 2007;120(13):1127-30.

24. Drogset JO, Strand T, Uppheim G, Odegard B, Boe A, Grontvedt T. Autologous patellar tendon and quadrupled hamstring grafts in anterior cruciate ligament reconstruction: a prospective randomized multicenter review of different fixation methods. Knee Surg Sports Traumatol Arthrosc. 2010;18(8):1085-93.

25. Ma CB, Francis K, Towers J, Irrgang J, Fu FH, Harner $\mathrm{CH}$. Hamstring anterior cruciate ligament reconstruction: a comparison of bioabsorbable interference screw and endobutton-post fixation. Arthroscopy. 2004;20(2):122-8.

26. Shen C, Jiang SD, Jiang LS, Dai LY. Bioabsorbable versus metallic interference screw fixation in anterior cruciate ligament reconstruction: a meta-analysis of randomized controlled trials. Arthroscopy. 2010;26(5):705-13.

27. Arnold MP, Kooloos J, van Kampen A. Single-incision technique misses the anatomical femoral anterior cruciate ligament insertion: a cadaver study. Knee Surg Sports Traumatol Arthrosc. 2001;9(4):194-9.

28. Harner CD, Honkamp NJ, Ranawat AS. Anteromedial portal technique for creating the anterior cruciate ligament femoral tunnel. Arthroscopy. 2008;24(1):113-5.

29. Streich NA, Friedrich K, Gotterbarm T, Schmitt H. Reconstruction of the ACL with a semitendinosus tendon graft: a prospective randomized single blinded comparison of double-bundle versus single-bundle technique in male athletes. Knee Surg Sports Traumatol Arthrosc. 2008;16(3):232-8.

30. Meredick RB, Vance KJ, Appleby D, Lubowitz JH. Outcome of single-bundle versus double-bundle reconstruction of the anterior cruciate ligament: a metaanalysis. Am J Sports Med. 2008;36(7):1414-21.

31. Ejerhed L, Kartus J, Kohler K, Sernert N, Brandsson S, Karlsson J. Preconditioning patellar tendon autografts in arthroscopic anterior cruciate ligament reconstruction: a prospective randomized study. Knee Surg Sports Traumatol Arthrosc. 2001;9(1):6-11.

32. Kim SG, Kurosawa H, Sakuraba K, Ikeda H, Takazawa S. The effect of initial graft tension on postoperative clinical outcome in anterior cruciate ligament reconstruction with semitendinosus tendon. Arch Orthop Trauma Surg. 2006;126(4):260-4.

33. Smith TO, Davies L, Hing CB. Early versus delayed surgery for anterior cruciate ligament reconstruction: a systematic review and meta-analysis. Knee Surg Sports Traumatol Arthrosc. 2010;18(3):304-11.

34. Da Silva RR, Matos MA, Silva DJA, Abreu MS. Associação entre tempo de ruptura do ligamento cruzado anterior e freqüência de outras lesões articulares do joelho. Rev Bras Ortop. 2006;41(7):268-71.

35. Birmingham TB, Bryant DM, Giffin JR, Litchfield RB, Kramer JF, Donner A, et al. A randomized controlled trial comparing the effectiveness of functional knee brace and neoprene sleeve use after anterior cruciate ligament reconstruction. Am J Sports Med. 2008;36(4):648-55.

36. Straw R, Colclough K, Geutjens GG. Arthroscopically assisted ACL reconstruction. Is a drain necessary? Knee. 2003;10(3):283-5.

37. McCormack RG, Greenhow RJ, Fogagnolo F, Shrier I. Intra-articular drain versus no drain after arthroscopic anterior cruciate ligament reconstruction: a randomized, prospective clinical trial. Arthroscopy. 2006;22(8):889-93.

38. Musil D, Sadovsky P, Stehlik J. [Intra-articular analgesia after anterior cruciate ligament reconstruction]. Acta Chir Orthop Traumatol Cech. 2007;74(3):182-8 
Annex 1 - Questionnaire on surgery and rehabilitation of anterior cruciate ligament $(A C L)$ lesions.

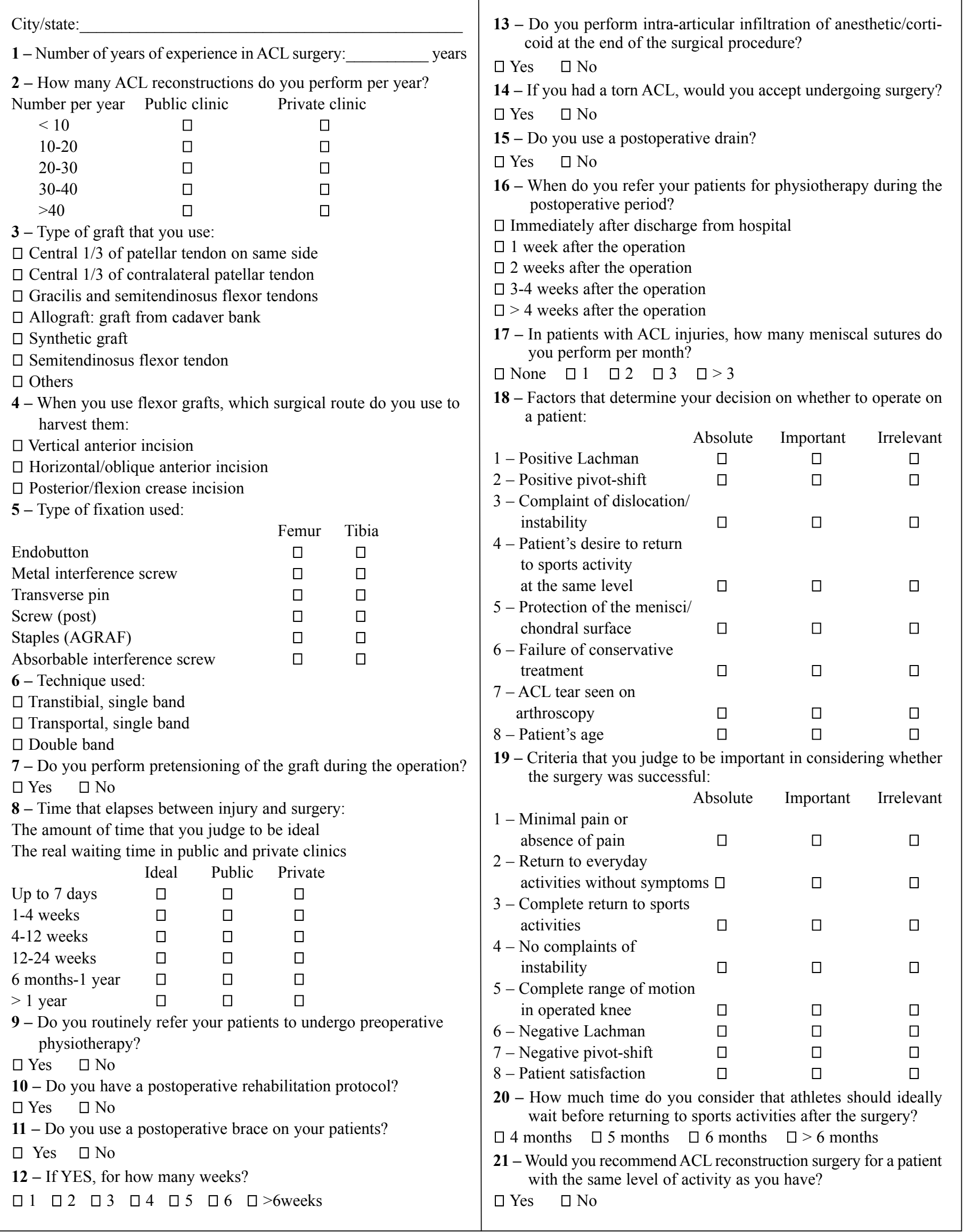

